
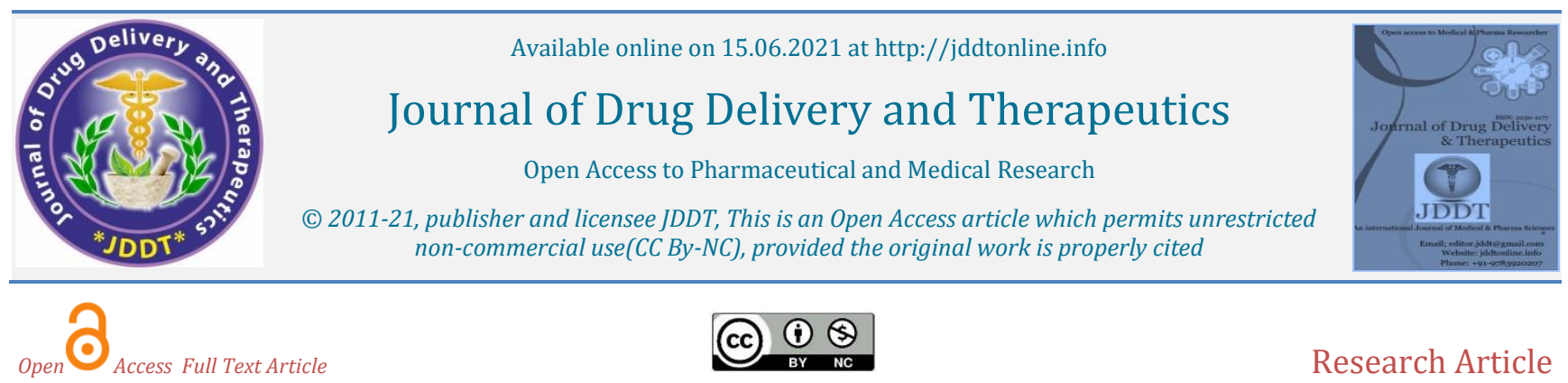

Research Article

\title{
Formulation and Evaluation of Lignocaine Hydrochloride Proniosomes Loaded Orabase for Dental Anaesthesia
}

\author{
G. V. Radha*, Myneni Ganesh Sai, N Sunayana, G. V. R. L. Soujanya, K. Charan \\ GITAM Institute of Pharmacy, GITAM Deemed to be University, Rushikonda, Visakhapatnam, Andhra Pradesh, India - 530045
}

\section{Article Info:

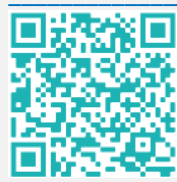 \\ Article History: \\ Received 19 April 2021 \\ Reviewed 23 May 2021 \\ Accepted 27 May 2021 \\ Published 15 June 2021}

\section{Cite this article as}

G.V. R, Myneni GS, N. S, G. V. R. L. S, K. C, Formulation and Evaluation of Lignocaine Hydrochloride Proniosomes Loaded Orabase for Dental Anaesthesia Journal of Drug Delivery and Therapeutics. 2021; $11(3-S): 27-34$

DOI: http://dx.doi.org/10.22270/jddt.v11i3-S.4866

\section{*Address for Correspondence:}

G. V. Radha, GITAM Institute of Pharmacy, GITAM Deemed to be University, Rushikonda,

Visakhapatnam, Andhra Pradesh, India - 530045

\section{Abstract}

The aim of this research is to prepare and evaluate lignocaine $\mathrm{HCl}$ Proniosomal orabase for enhanced permeation and prolonged dental anaesthesia effect. Objective: Various lignocaine proniosomal gels were formulated employing various surfactants. Methods: The formulations were scrutinized for entrapment efficiency, optical microscopy, in-vitro diffusion and release studies, mucoadhesive strength, ex-vivo permeation studies and drug - excipient interactions were determined by FTIR spectroscopy. Results: span 80 was found to be superior and significant for loading in to orabase. Considering the best entrapment efficiency with span $80(91.60 \%)$ and optimum vesicle shape, along with prolonged drug permeation (33.6\% for $24 \mathrm{~h}$ ) the formulation $\mathrm{F} 4$ was selected and optimized for loading into orabase. The formulation F4 loaded orabase exhibited significant prolonged release over $10 \mathrm{~h}$, and permeation profiles exhibited nearly two fold increased flux in comparison with control. Good mucoadhesive strength was observed for proniosomal orabase 6273 dynes $/ \mathrm{cm}^{2}$, No evidence of incompatibility amongst formulation components from FTIR studies. SEM images revealed the particle size range from $50 \mu \mathrm{mt}$ to $100 \mu \mathrm{mt}$ for proniosomal orabase. Conclusion: Orabase can be an effective carrier for proniosomes with enhanced retention time at the site of application and provide prolonged release for oro-dental conditions.

Keywords: lignocaine Hcl, Oro-dental anaesthesia, Proniosomal gel, Orabase, Entrapment efficiency, prolonged release.

\section{INTRODUCTION}

Orabase is an effective mucoadhesive base effectively employed as a drug carrier, considered as a hydrophobic gel or dental paste. The aim of the present investigation was to achieve the prolonged release of Lignocaine $\mathrm{HCl}$ by loading in proniosome ${ }^{1-3}$ vesicles and improve its retention time at the particular site of action by incorporating drug loaded proniosomes into orabase this significantly reduces dosage frequency hence increase patient compliance.

Orabase is one of the most effective bio adhesive bases that have been used for pain relief incurred in the management of oral aphthous stomatitis. Used as drug carrier. It is considered as hydrophobic gel, dental paste or sometimes is referred to as an ointment due to the presence of high portion of liquid paraffin in its constituents ${ }^{2}$. The base consists of gelatin, pectin, mineral oil and sodium carboxymethyl cellulose in a hydrocarbon gel $^{2}$. It is used for temporary relief of symptoms associated with oral inflammation and ulcerative lesions ${ }^{3}$. Based on prior experience of their use in the food industry and medicine, these ingredients are considered safe and have not been associated with adverse events that can be attributed to their use.

Lignocaine is 2-(diethyl amino)- $\mathrm{N}-(2$, 6-dimethylphenyl) acetamide hydrochloride. Lignocaine is an aminoethylamide and a prototypical member of the amide class anaesthetics. It is a local anaesthetic and is effective in pain relief and inflammation. Lignocaine hydrochloride is a local anaesthetic and cardiac depressant used as an anti-arrhythmia agent. Its actions are more intense and its effects more prolonged than those of procaine but its duration of action is shorter than that of bupivacaine or prilocaine.

Proniosomes are dehydrated preparations employing suitable non-ionic surfactants and carrier, the preparation further yields niosomes on hydration with water ${ }^{4}, 5$. Niosomes are proven to be best carriers for drug targeting, relatively less toxic, stable, and economical and better permeation than liposomes 6 .

\section{MATERIALS AND METHODS:}

\section{Materials}

Lignocaine Hcl was a gift sample from Techno drugs and Intermediates, Panoli, Span 20, Span 40, were purchased from Loba chemicals limited Mumbai Span 60, Span 80 and poly ethylene glycol were purchased from Molechem, Mumbai, Cholesterol was purchased from Finar chemicals, Ahmadabad, soya lecithin was purchased from Sigma chemicals, Ahmadabad , sodium carboxymethyl cellulose was purchased from Reachem Lab Chem. Pvt Ltd, Chennai, gelatin and pectin were purchased from Fisher scientific Ltd Mumbai, Liquid paraffin was purchased from Thermo Fisher Scientific Ltd, Mumbai. 


\section{Methods}

\section{Preparation of Lignocaine $\mathrm{HCl}$ proniosomal gel:}

Lignocaine $\mathrm{HCl}$ proniosomal gel was prepared by a coacervation phase separation method. Exactly weighed amounts of surfactant, lecithin, and cholesterol were taken in clean and dry wide mouthed glass beaker and drug was dissolved in alcohol $(2.5 \mathrm{ml})$ was added to it. All the ingredients were mixed well with a glass rod the open end of the glass bottle was covered with a lid to prevent the loss of solvent from it and warm over water bath shaker at $65^{\circ} \mathrm{C}$ for about five minutes till the chemical agent mixture was dissolved fully. Then the $1 \mathrm{ml}$ of phosphate buffer 6.8 was added until a formulation was formed that was converted into Proniosomal gel on cooling. The gel therefore obtained was preserved within the same glass bottle in dark conditions for characterization.

Table 1: Composition of the proniosomal formulation of lignocaine Hcl

\begin{tabular}{lllllll}
\hline $\begin{array}{l}\text { S. } \\
\text { No }\end{array}$ & Formulation & Surfactant & $\begin{array}{l}\text { Surfactant } \\
\text { Concentration }\end{array}$ & Cholesterol & \multicolumn{2}{c}{$\begin{array}{l}\text { Soya } \\
\text { lecithin }\end{array}$} \\
\hline 1. & F1 & Span 20 & $468 \mathrm{mg}$ & $54 \mathrm{mg}$ & $468 \mathrm{mg}$ & $20 \mathrm{mg}$ \\
2. & F2 & Span 40 & $468 \mathrm{mg}$ & $54 \mathrm{mg}$ & $468 \mathrm{mg}$ & $20 \mathrm{mg}$ \\
3. & F3 & Span 60 & $468 \mathrm{mg}$ & $54 \mathrm{mg}$ & $468 \mathrm{mg}$ & $20 \mathrm{mg}$ \\
4. & F4 & Span 80 & $468 \mathrm{mg}$ & $54 \mathrm{mg}$ & $468 \mathrm{mg}$ & $20 \mathrm{mg}$ \\
\hline
\end{tabular}

\section{Entrapment efficiency}

Proniosomal formulations $(0.2 \mathrm{~g})$ after reconstitution with sufficient aqueous buffer ( $\mathrm{pH}$ 6.8) in suitable centrifuge tube were executed for centrifugation using a cooling centrifuge at $3500 \mathrm{rpm}$ for about $1 \mathrm{~h}$ at $4^{\circ} \mathrm{C}^{7}$. The clear and distinct supernatant was collected carefully to separate unentrapped drug, and the sediment was then treated with ethanol $(1 \mathrm{ml})$ to lyse the vesicles and diluted with ethanol respectively, and absorbances were determined spectrophotometrically at 264 $\mathrm{nm}$. The entrapment efficiency was determined using the following equation.

$$
\% E . E=1-\frac{(\text { Unentrapped Drug })}{(\text { Total Drug })} \times 100
$$

\section{Optical microscopy}

The vesicle formation by the particular procedure was confirmed by optical microscopy in $10 \mathrm{X}$ and $45 \mathrm{X}$ resolutions. Proniosomal gel before hydration clear liquid crystalline state was observed then upon hydration niosomal suspension made was placed over a glass slide and determined for the formation of vesicles.

\section{In vitro diffusion}

In vitro release studies were performed for the preparations using Franz diffusion cell. Dialysis membrane was positioned between receptor and donor compartments, an equivalent dose of lignocaine $\mathrm{Hcl}$ preparation was introduced on the membrane, receptor compartment was charged with $\mathrm{pH} 6.8$ buffer $(15 \mathrm{ml})$. Cells were conditioned at $37 \pm 5^{\circ} \mathrm{C}$ with stirring at $500 \mathrm{rpm}$. At predetermined time periods aliquots were withdrawn from the receptor compartment, respectively and the same was replenished with fresh buffer. The samples were analysed spectrophotometrically.

\section{Preparation of lignocaine Hcl Proniosomal orabase}

Orabase gel was prepared by mixing required ratios of gelatin, pectin, Na CMC and PEG, liquid paraffin. These are transferred into a clean glass motor and pestle and triturated. Then the required amount of proniosomal gel was added with continuous stirring until a homogenous mixture is formed.

\section{Preparation of lignocaine Hcl orabase}

Orabase gel was prepared by mixing required ratios of gelatin, pectin, Na CMC and PEG, liquid paraffin. These are transferred into a clean glass motor and pestle and triturated. Then the required amount of lignocaine Hcl was added with continuous stirring until a homogenous mixture is formed.

\section{pH determination:}

A suitable quantity of orabase was accurately weighed and dispersed in $10 \mathrm{ml}$ of purified water. The $\mathrm{pH}$ of the dispersion formed was measured using a digital $\mathrm{pH}$ meter.

\section{In vitro release studies of Proniosomal orabase and drug orabase:}

In vitro release studies on proniosomal orabase and drug orabase were performed by using dialysis membrane ${ }^{8}$. The capacity of the receptor compartment was $15 \mathrm{ml}$. The area of the donor compartment exposed to receptor compartment was $4.90 \mathrm{~cm}^{2}$. Cellophane membrane was soaked in phosphate buffer pH 6.8 for $1 \mathrm{hr}$ before carrying the experiment. The dialysis cellophane membrane was mounted between the donor and receptor compartment. A quantity drug equivalent of $3 \mathrm{mg}$ proniosomal orabase was placed on one side of the dialysis membrane. The receptor medium was phosphate buffer $\mathrm{pH}$ 6.8. The receptor compartment was enclosed by a vessel to take care of the temperature at $37^{\circ} \mathrm{C}$. Heat was provided by using a hot plate with a magnetic stirrer. The receptor fluid was stirred by a magnetic bead fitted to a magnetic stirrer. At every sampling interval of $1 \mathrm{hr}, 5 \mathrm{ml}$ sample were withdrawn and were replaced by equal volumes of fresh receptor fluid on every occasion $^{9}$. Same procedure was repeated for drug orabase.

\section{Determination of mucoadhesive strength of the proniosomal orabase formulation}

It was measured by the force required to detach the formulation from oral mucosa using an adopted balance. Freshly excised oral mucosa membrane was used as a model tissue. Equal pieces $(2.5 \times 2.5 \mathrm{~cm})$ cut from oral mucosa membranes ${ }^{10}$, were horizontally fixed to the upper stage of the modified balance keeping the mucosal side out. Gel samples $(0.5 \mathrm{~g})$ were placed on the lower steel stage so that the surface of the sample contacted to the mucosal membrane adhered to the upper stage ${ }^{11,12}$. The sample was left in contact with the mucosal membrane for $5 \mathrm{~min}$ to ensure intimate contact. Water was added drop wise to the pan on the other side of the device, until the mucosal detached from the gel sample. The mucoadhesive force, detachment stress in dyne $/ \mathrm{cm}^{2}$, was determined from the minimum amount of water required to detach the 
formulation from the oral mucosa surface using following equation ${ }^{13}$ :

$$
\text { Detachment stress }=\mathrm{m} \times \frac{\mathrm{g}}{\mathrm{A}}
$$

Where $\mathrm{m}$ is the weight of water added to the balance in gram, $\mathrm{g}$ is acceleration due to gravity $\left(980 \mathrm{~cm} / \mathrm{s}^{2}\right)$, and $\mathrm{A}$ is an area of tissue exposed in $\mathrm{cm}^{2}$.

\section{Ex vivo permeation studies of proniosomal orabase and drug orabase}

Permeation of selected proniosomal orabase formulation through excised buccal mucosa was carried out in a modified Franz diffusion cell with diffusion area of $4.90 \mathrm{~cm}^{2}$. The buccal mucosa membrane was placed between donor \& receptor compartment with the mucosal side facing the gel sample in the donor cell. Before the experiment, the buccal mucosa was equilibrated in simulated saliva fluid $(\mathrm{pH}$ 6.8) for $1 \mathrm{hr}$. sample of proniosomal orabase was placed in the donor compartment. The receiving compartment contained $100 \mathrm{ml}$ of phosphate buffer 6.8 maintained at temperature $37 \pm 0.5{ }^{\circ} \mathrm{C}$ stirring was achieved with a magnetic stirrer at 50 $\mathrm{rpm}$. Samples are withdrawn at various time intervals up to $24 \mathrm{~h}$ and replaced by simulated saliva fluid to maintain constant volume \& sink conditions. The samples were assayed spectrophotometrically at $264 \mathrm{~nm}$. The amount of drug permeated into the receptor compartment was plotted against time. According to Fick's first law, the drug steadystate flux $J_{\mathrm{ss}}\left(\mu \mathrm{g} / \mathrm{cm}^{2} / \mathrm{h}^{-1}\right)$ was obtained from the resultant slop of straight portion of the amount of drug permeated per unit area against time plot ${ }^{14}$. The permeability coefficient $\left(\mathrm{k}_{\mathrm{p}}\right)$ was calculated by dividing $\mathrm{J}_{\mathrm{ss}}$ with initial concentration of lignocaine in donor compartment. Same procedure was carried out for drug orabase.

$$
\mathrm{K}_{\mathrm{p}}=\mathrm{J}_{\mathrm{ss}} / \mathrm{C}_{\text {donor }}
$$

The flux of drug was calculated using $\mathrm{J}_{s s}$ formula i.e,.

$$
\mathrm{J}_{\mathrm{ss}}=\frac{\text { amount of drug permeated }}{\text { time } \times \text { area of membrane }} \times \text { area of the membrane }
$$

The permeation coefficient of the drug was calculated using formula

$$
\mathrm{K}_{\mathrm{p}}=\frac{\text { flux }}{\text { initial concentration of drug in donar chamber }}
$$

The $\mathrm{D}_{\mathrm{o}}$ value was calculated using slope equation i.e,

$$
\text { Slope } y=m x+c
$$

\section{Determination of drug deposited into oral mucosa}

The amount of the drug deposited in the oral mucosa was determined. The oral mucosal membrane was removed from the diffusion cell after $24 \mathrm{~h}$ of permeation study, and washed carefully with distilled water for $10 \mathrm{sec}$ to remove the adhering gel formulation. The skin was sonicated in $10 \mathrm{ml}$ ethanol for 30 mins to leach out the drug. Then ethanol was assayed spectrophotometrically for Lignocaine $\mathrm{HCl}$ content.

\section{Optical microscopy of proniosomal orabase and drug orabase}

The vesicle formation by the particular procedure was confirmed by optical microscopy in $10 \mathrm{X}$ and $45 \mathrm{X}$ resolutions. Proniosomal orabase before hydration clear liquid crystalline state was observed then upon hydration niosomal orabase made was placed over a glass slide and glued over by drying at space temperature, the dry skinny film of niosomal orabase determined for the formation of vesicles. The photomicrograph of the preparation additionally obtained from the magnifier by employing a camera.

\section{FTIR studies}

Fourier transform infrared spectroscopy (FT-IR) is a simple technique for the detection of changes within excipient drug mixture. Disappearance of an absorption peak or reduction of the peak intensity combined with the appearance of new peaks give a clear evidence for interactions between drug and excipient. FTIR spectra of drug and excipients were mixed in combinations and were obtained by the conventional $\mathrm{KBr}$ disc/pellet method. The sample was grounded gently with anhydrous $\mathrm{KBr}$ and compressed to form pellet. The scanning range was 400 and $4000 \mathrm{~cm}^{-1}$.

\section{Kinetic analysis of the in-vitro release data}

To ascertain the kinetic modelling of drug release, the release data of Lignocaine $\mathrm{HCl}$ from the proniosomal gels was fitted to zero-order, first-order, and Higuchi equations.

\section{Zero order:}

$$
\mathrm{M}_{\mathrm{t}}=\mathrm{M}_{\mathrm{o}}+\mathrm{k}_{\mathrm{o}} \mathrm{t}
$$

Where Mt is the amount of drug released at time $t$; Mo the amount of drug in the solution at $t=0 ;\left(\right.$ usually, $\left.M_{o}=0\right)$ and $\mathrm{k}_{\mathrm{o}}$ the zero-order release constant

\section{First order:}

$$
\mathrm{M}_{\mathrm{t}}=\mathrm{M}_{\infty}\left(1+\mathrm{e}^{\mathrm{K}_{1} \mathrm{t}}\right)
$$

$\mathrm{M}_{\infty}$ is the total amount of drug in the matrix and $\mathrm{k}_{1}$ the firstorder kinetic constant.

\section{Scanning electron microscopy (SEM)}

Particle size of Lignocaine $\mathrm{HCl}$ proniosomal orabase is a factor of prime importance. The surface morphology and size distribution of proniosomal orabase was studied by SEM. A double-sided tape that was affixed on aluminium stubs and the proniosomal powder was spread on it. The aluminium stub was placed in a vacuum chamber of scanning electron microscope (Carl Zeiss Micro Imaging, acceleration voltage$3.00 \mathrm{KV}$, Mumbai). The morphological characterization of the samples was observed using a gaseous secondary electron detector ${ }^{15}$.

\section{In vivo studies:}

The Lignocaine proniosomal gel (test) and 2\% Lignocaine $\mathrm{HCl}$ marketed gel (control) was applied to the shaved ventral side of male Wister rats with the dose of $1 \mathrm{mg} / \mathrm{kg}, 30 \mathrm{~min}$ before the beginning of the test. The pricking method was used to assess the anaesthetic activity of prepared proniosomal gel. The time taken to start the abdomen lift or sudden run of rat was observed (measured at various time intervals) and it was called the reaction time. The maximum response (MR) to the lignocaine $\mathrm{HCl}$ proniosomal gel in terms of reaction time in hours which reflects the intensity of drug action.

\section{RESULTS AND DISCUSSION}

To obtain appropriate vesicular formulation for delivery of lignocaine $\mathrm{Hcl}$ in oral cavity for dental anesthesia, various proniosomal systems were formulated employing cholesterol and lecithin as membrane stabilizers along with a range of non - ionic surfactants, span $(20,40,60$ and 80$)$ proniosomal gel systems were formulated for effective incorporation broad range of actives. Non - ionic surfactants employed non - toxic and compatible with the biological system. The systems were formulated by blending vesicular components with alcohol and aqueous phase yielding concentrated a liquid crystalline system that produces niosomal dispersion instantaneously on exposure to saliva in 
the oral cavity. Formulations pertaining to span 80 and 60 evinced semisolid consistency, whereas span 40 and 20 exhibited liquid consistency.

\section{Entrapment efficiency}

For a better pharmaceutical perspective, entrapment efficiency is a consequential parameter for collating various proniosomal formulations. Lignocaine $\mathrm{Hcl}$ is incorporated into vesicles. The formulation comprising span 80 exhibited highest entrapment efficiency over other spans, span 20 showed minimal entrapment efficiency; observed variation with entrapment efficiencies of different surfactants is the consequence of diverse structure and length of alkyl chain used as surfactants. The entrapment efficiencies of the respective formulation are presented in (fig. 1).

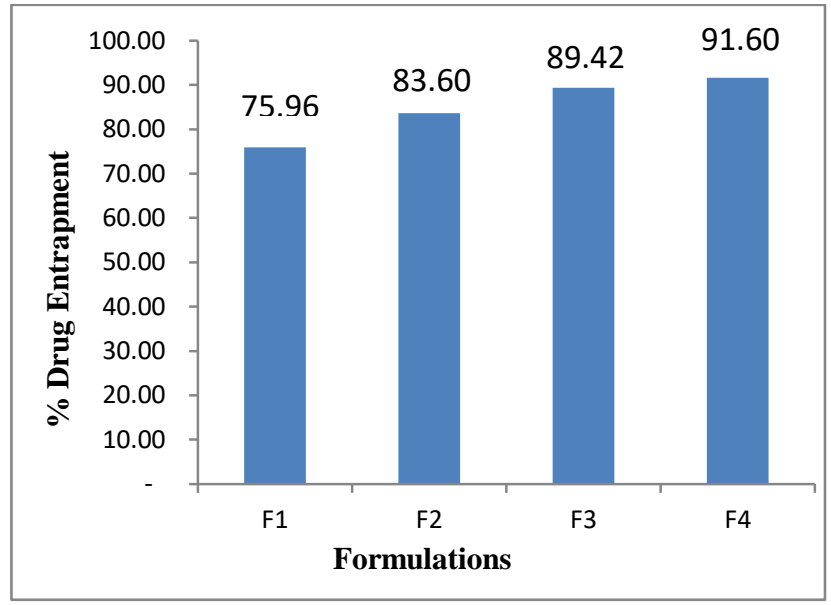

Figure 1: Entrapment efficiency of formulated proniosomes

\section{Optical Microscopy}

The size of the formed vesicles has a major contribution towards in vivo fate. From (fig. 2 and fig. 3 ) it is observed that the shape of proniosomal (F1- F4) formulations exhibited, following yields niosomes with spherical morphology on $10 \mathrm{X}$ and $45 \mathrm{X}$ magnifications.

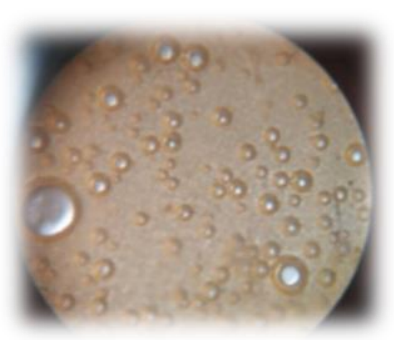

Span 20

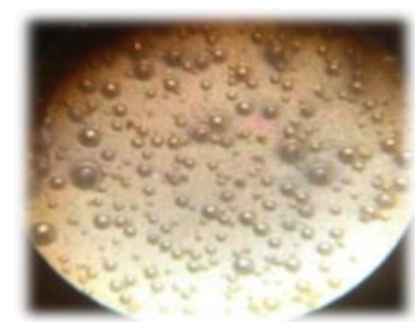

Span 60

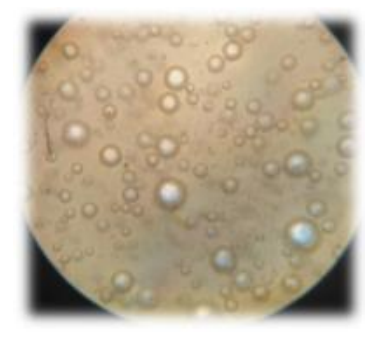

Span 40

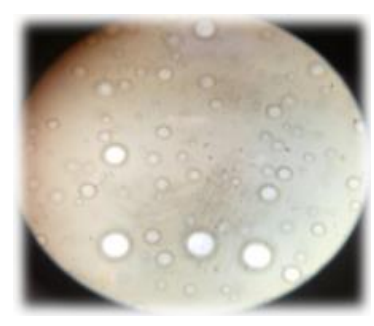

Span 80
Figure 2: Optical microscopic images of proniosomal formulations (10X magnification)

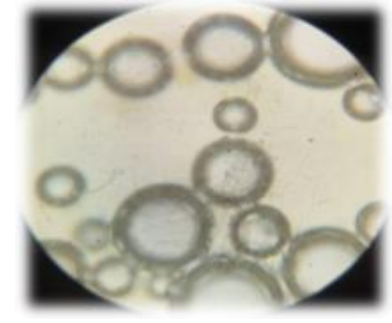

Span 20

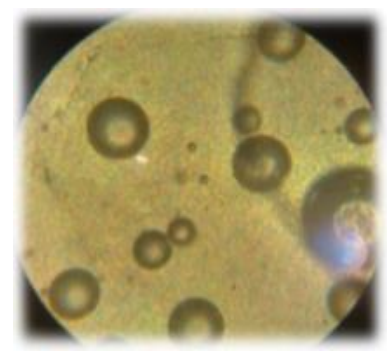

Span 60

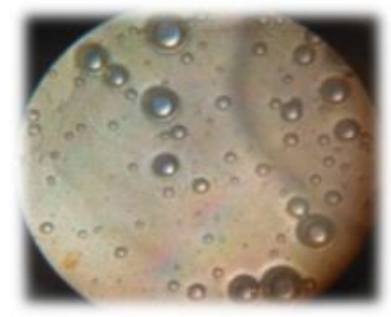

Span 40

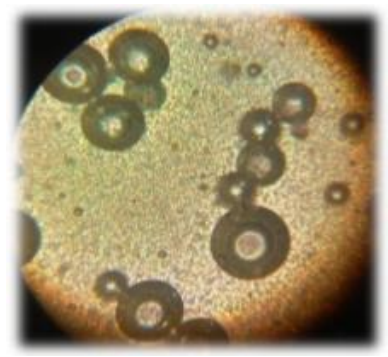

Span 80
Figure 3: Optical microscopic images of proniosomal formulations (45X magnification)

\section{In vitro diffusion}

Amongst the different formulations, F4 showed 33.6\% drug release for 24hour diffusion as shown in (fig 4). Consequently, formulation F4 exhibited higher diffusion as compared to F1 - F3. Commonly the release profiles of the proniosomal systems predominantly depended on hydrophobic lipophilic balance (HLB) value besides the alkyl chain length.

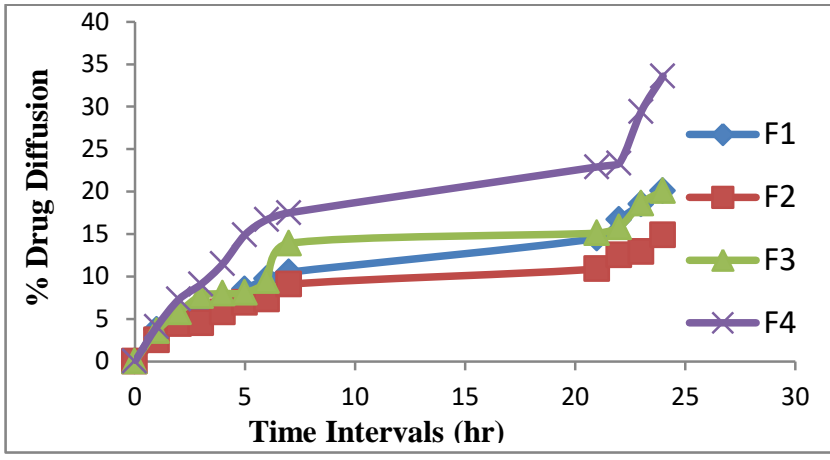

Figure 4: In vitro diffusion profile of proniosomal formulations data

\section{Lignocaine proniosomal orabase}

From the in vitro diffusion profile, with F4 showing prominent profile compared to F1 - F3 respectively, consequently F4 was incorporated into orabase, enabling increased retention time within oral mucosa.

\section{Lignocaine orabase}

Lignocaine was directly incorporated into orabase as a control for comparison with the proniosomal orabase.

\section{pH determination:}

The $\mathrm{pH}$ of the orabase was found as 6.8. Therefore it is having neutral $\mathrm{pH}$. And can be administered for orodental anaesthesia.

\section{In vitro release studies of Proniosomal orabase and drug orabase:}

Release profiles comprehend the efficiency in the delivery of the drug by the proposed system. Complete release from Lignocaine $\mathrm{Hcl}$ loaded orabase was achieved within $5 \mathrm{~h}$ 
which verify the aptitude of the drug to permeate through the membrane. It was learned the release of lignocaine Hcl proniosome system exhibited significantly lower release rates compared to control. This specifies that the lipid bilayer of niosomes limits drug release. An interrelation between the entrapment efficiency and the drug release was scrutinized. The higher proportion of drug entrapped within vesicles, the slower the release profile. The release from proniosomal orabase was slow and spread over $12 \mathrm{~h}$, compared to lignocaine $\mathrm{Hcl}$ orabase with a complete release within a few hours. Significantly the release of the proniosomal orabase formulation was protracted than that of lignocaine $\mathrm{Hcl}$ loaded orabase. The release profiles of proniosomal orabase and lignocaine Hcl loaded orabase are shown in (fig. 5).

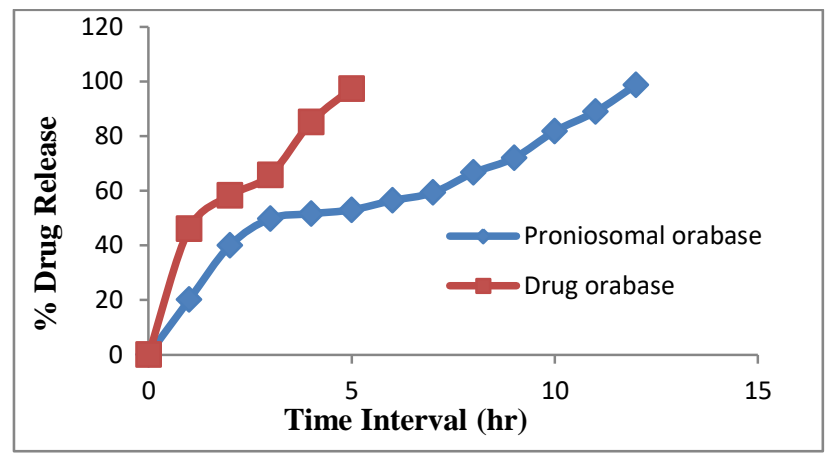

Figure 5: In vitro release profiles of proniosomal and drug orabase data

\section{Determination of mucoadhesive strength of the proniosomal orabase formulation}

Mucoadhesive strength can be related to fracture theory. The adhesive bond between systems is linked to the force needed to detach surfaces from each other. This theory is associated with the force required for polymer separation from the mucus to their adhesive bond strength. The weight applied to detach the mucous from the proniosomal gel was found to be 6273dynes $/ \mathrm{cm}^{2}$.

\section{Ex vivo permeation studies of proniosomal orabase and drug orabase}

After local administration in the oral cavity and hydration by saliva, Lignocaine Hcl proniosomal gels are converted into niosomal vesicles. The formed niosomal vesicles enhance the penetration of the trapped drug across the mucosal membrane into the circulation according to the following mechanisms:

1. Increasing the driving force of lipophilic drug permeation through the adsorption and fusion of intact niosomes to the mucosal membrane surface that simultaneously increases the thermodynamic activity gradient of drug at the interface.

2. Reduction of the barrier properties of mucosal epithelium and increase its fluidity due to their penetration enhancer property.

3. Ethanol present in the proniosomal gel formulation acts as a penetration enhancer as well as provides soft flexible characteristics to the vesicles that allow them to easily penetrate the mucosa and enter the systemic circulation.

The percent of drug permeated result was shown in (Fig. 6). The flux of drug was calculated using Jss formula i.e,

And the flux for $24^{\text {th }}$ hour was found to be $74 \mu \mathrm{g} / \mathrm{cm}^{2} / \mathrm{hr}$.

The permeation coefficient of the drug was found to be 2.46 $\mathrm{cm}^{2} / \mathrm{hr}$

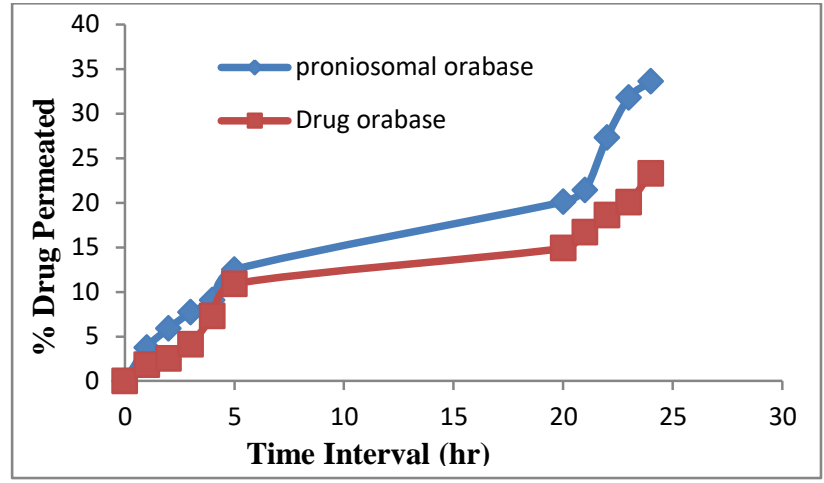

Figure 6: Ex vivo permeation studies

\section{Estimation of drug deposited in the oral mucosa}

The drug was deposited in the oral mucosa with the selected Lignocaine $\mathrm{HCl}$ proniosomal gel formulation. The \% of drug retained in oral mucosa was found to be $87.25 \%$. Lignocaine $\mathrm{HCl}$ proniosomal orabase formulation showed significant deposition within the oral mucosal layer. This reveals that potential of these intact nano-sized niosomes to overcome the epithelium barrier of the oral mucosa \& concentrate the drug within the mucosal layers.

\section{Optical microscopy Lignocaine $\mathrm{HCl}$ Proniosomal orabase}

The proniosomal orabase before and after hydration was observed as shown in the fig. 7 under $10 \mathrm{X}$ and $45 \mathrm{X}$ magnifications.
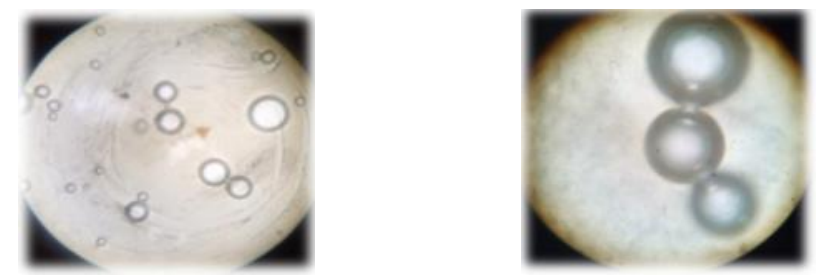

Figure 7: proniosomal orabase under a. 10X and b. $45 \mathrm{X}$ magnification

\section{Lignocaine $\mathrm{HCl}$ orabase}

The drug orabase before and after hydration was observed as shown in the figure 8 under $10 \mathrm{X}$ and $45 \mathrm{X}$ magnifications.
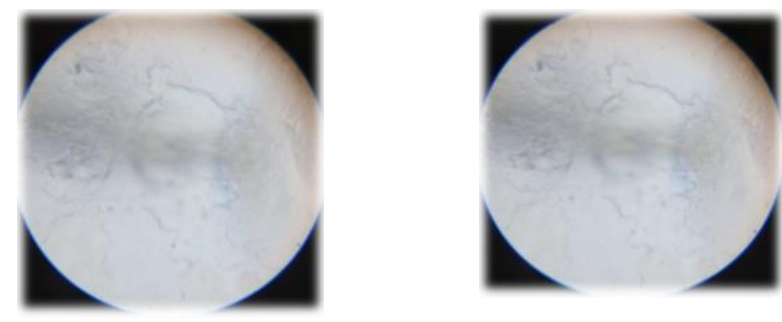

Figure 8: drug orabase under a. $10 \mathrm{X}$ and b. $45 \mathrm{X}$ magnification

\section{FTIR Results:}

FTIR studies were done for Lignocaine $\mathrm{HCl}$ pure drug, proniosomal orabase and drug orabase and are in shown in table (2). From these studies concluded that there is slight change in the peak of the spectrums of drug and excipients mixture. In recent observation there was no considerable variation in dosage stability and used excipients was found. Individuality peaks of lignocaine $\mathrm{HCl}$ were clearly established without any interaction of excipients used in proniosomal orabase formulation (as shown in figure 9,10 ). 


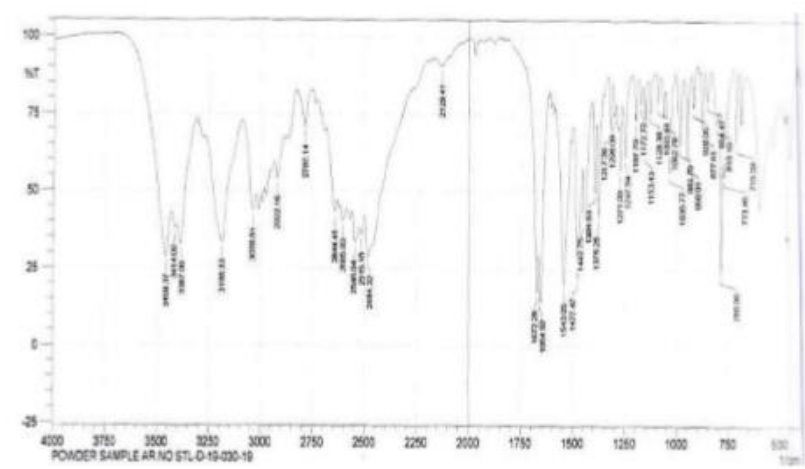

Figure 9: FTIR lignocaine Hcl pure drug:

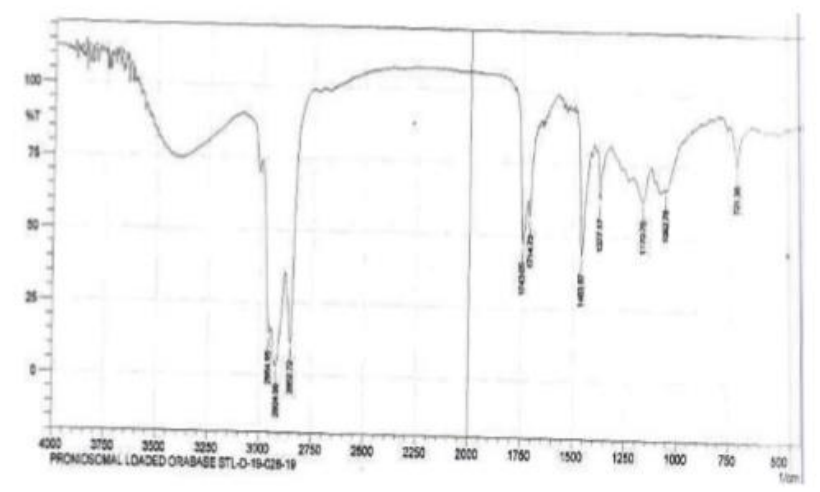

Figure 10: FTIR lignocaine Hcl Proniosomal orabase

Table 2: FTIR bands of lignocaine Hcl proniosomal orabase and lignocaine Hcl orabase

\begin{tabular}{lll}
\hline Functional group & $\begin{array}{l}\text { IR band of lignocaine Hcl pure drug } \\
\left(\mathbf{c m}^{-1}\right)\end{array}$ & $\begin{array}{l}\text { IR band of lignocaine Hcl } \\
\text { proniosomal orabase }\left(\mathbf{c m}^{-1}\right)\end{array}$ \\
\hline N-H bending & 3458.37 & 3500 \\
Alkane bending & 2922.16 & 2924 \\
Amide & 1654.92 & 1650.65 \\
N-H stretching & 1543.05 & 1550 \\
C-N & 1375.25 & 1377.17 \\
\hline
\end{tabular}

\section{SEM results}

The observed SEM images revealed the well identified spherical morphology of Lignocaine $\mathrm{HCl}$ proniosomal orabase, post hydration prepared employing span 80, increased vesicles size greatly lowers mucosal penetration considering the above mentioned size distribution was examined, and the formulation exhibited particle size ranges from $50 \mu \mathrm{mt}$ to $100 \mu \mathrm{mt}$ as shown in the figure(11) under 100X magnification conferring enhanced mucosal penetration.

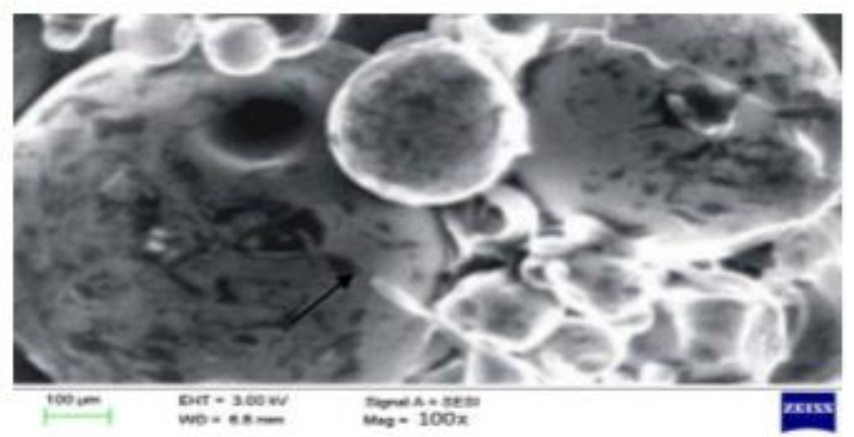

Figure 11: SEM studies of Lignocaine $\mathrm{HCl}$ proniosomal orabase under $100 \mathrm{X}$ magnification.

\section{Kinetic analysis of the in vitro release data}

Mathematical models are commonly used to predict the release mechanism and to compare release profile. For all the formulations, the release kinetics was tested for zero order (direct relation between cumulative percent drug released and time), first order (direct relation between log cumulative percent drug remaining and time) and diffusion (direct relations between cumulative percent of drug release and square root of time) kinetic models. The regression coefficient $\left(\mathrm{r}^{2}\right)$ was used as an indicator of the best fit for each of the considered models.
Based on the kinetics of release studies the drug release follows Higuchi diffusion and based on the $\mathrm{n}$ value from Peppas equation it's clearly indicated that it follows non fickian diffusion.

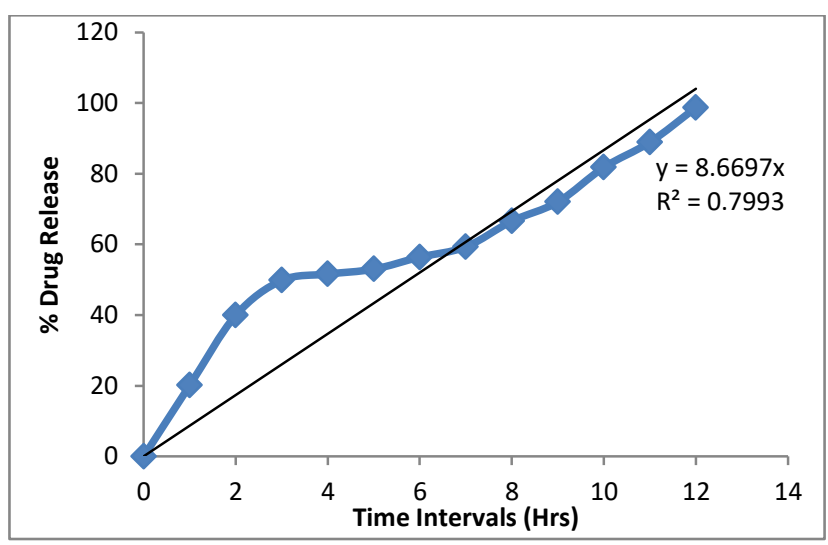

Figure 12: zero order release kinetics of the formulation

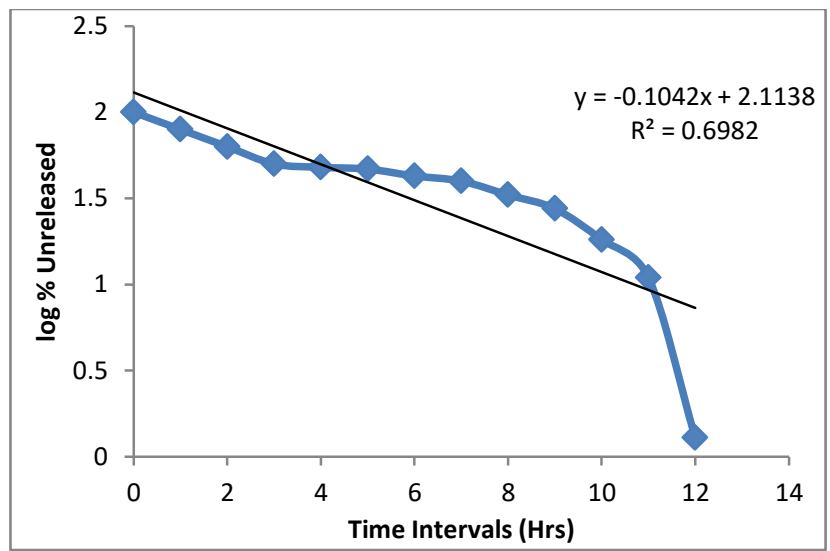

Figure 13: First order kinetics of the formulation 


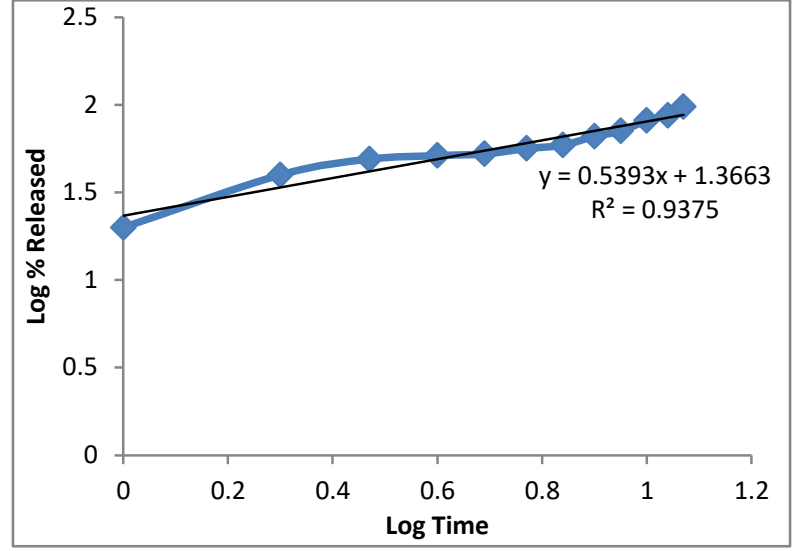

Figure 14: Peppas order kinetics of the formulation

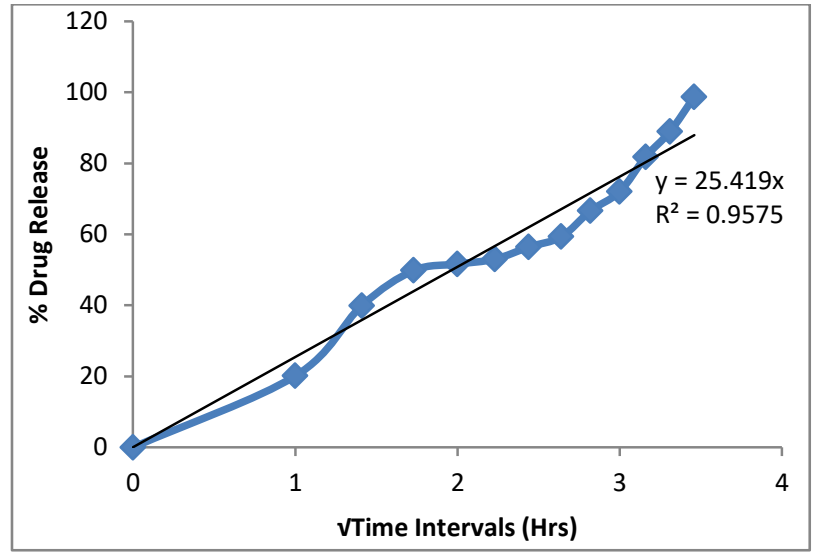

Figure 15: Higuchi order kinetics of the formulation

Table 3: Release kinetics of Lignocaine $\mathrm{HCl}$ proniosomal orabase

\begin{tabular}{lll}
\hline Order of kinetics & Rate constant (k) & $\mathbf{r}^{2}$ value \\
\hline Zero order & 8.6697 & 0.7993 \\
First order & 0.1042 & 0.6982 \\
Peppas & 0.5393 & 0.9375 \\
Higuchi & 25.419 & 0.9575 \\
\hline
\end{tabular}

\section{In vivo studies}

The Lignocaine $\mathrm{HCl}$ proniosomal gel (test) and marketed $2 \%$ Lignocaine $\mathrm{HCl}$ gel (control) was applied to the shaved ventral side of male Wister rats, and it was observed that the lignocaine $\mathrm{HCl}$ proniosomal gel (test) showed more than 10 hours while the marketed gel (control) showed only 5 hours of duration of anaesthetic action.

Table 4: In vivo analgesic activity of lignocaine $\mathrm{HCl}$ proniosomal gel and marketed formulation.

\begin{tabular}{lll}
\hline Formulation & Reaction time (hr) & Duration of drug action (hr) \\
\hline Lignocaine Hcl Proniosomal gel & 10 minutes \pm 1 minute & 8 \\
Marketed Lignocaine gel & 5 minutes \pm 1 minute & 5 \\
\hline
\end{tabular}

\section{CONCLUSION}

Endeavouring effort was made in preparing much safer and an alternative for oral route. Considering proniosomal gels in which lignocaine $\mathrm{HCl}$ was successfully entrapped with high efficiency into vesicles. Proniosomal gel formulation F4, considered optimal formulation with EE\% (91.6\%) post reconstitution. As a result, the optimal formula was further incorporated into orabase for good mucoadhesive behaviour essential to achieve increased retention for prolonged anaesthetic effect. The formula exhibited significant permeation with increased flux and sustained for longer periods compared to the lignocaine $\mathrm{HCl}$ gel control at the same dose level. Hence, orabase loaded with proniosomal gels may be a promising carrier for anesthetics in dental treatments with their intact vesicles and safety aspects for local action for longer periods with simple preparation technique.

\section{Acknowledgement}

The authors are grateful to GITAM Institute of Pharmacy, GITAM (Deemed to be University), Visakhapatnam for providing necessary facilities and support.

\section{Conflict of Interests}

All authors have none to declare.

\section{REFERENCES}

1. Kakr R, Rao R, Goswami A, Nanda S, Saroha K. Proniosomes: An emerging vesicular system in drug delivery and cosmetics. Der Pharmacia Lettre 2010; 2:227-239.

2. G.V. R, K. Tridev S, P. P, P. B, J. R, studied on Aceclofenac loaded proniosomal orabase for management of dental pain. International Journal of Applied Pharmaceutics, 2018; 10(6).

3. Walve JR, Rane BR, Gujrathi NA. Proniosomes: A surrogate carrier for improved transdermal drug delivery system. Int J Res Ayurveda Pharm 2011; 2:743-750.

4. Dua JS, Rana AC, Bhandari AK. Liposomes methods of preparation and applications. Int J Pharm Stud Res 2012; 3:14-20.

5. Mujoriya RZ, Dhamandeb K, Bodla RB. Niosomal drug delivery systems-a review. Int J Appl Pharm 2011; 3:7-10.

6. Akhilesh D, Prabhu P, Faishal G. Comparative study of carriers used in proniosomes. Int J Pharm Chem Sci 2012; 4:307-314.

7. Mokhtar M, Sammour OA, Hammad MA, Megrab NA, Impact of some formulation parameters on flurbiprofen encapsulation and release rates of niosomes containing from proniosomes. AAPS PharmSciTech 2008; 9:782 - 790. https://doi.org/10.1208/s12249-008-9114-0

8. Devaraj GN, Parakh SR, Devraj R, Apte SS, Rao BR, Rambhau D, Release studies on niosomes containing fatty alcohols as bilayer 
stabilizers instead of cholesterol; J Colloid Interface Sci; 2002; 251:360-365. https://doi.org/10.1006/jcis.2002.8399

9. Hanan Jalal Kassab, Lena Mura Thomas, Saba Abdulhabi Jabir, Development and physical characterization of a periodontal bioadhesive gel of gatifloxacin, Int. J Appl. Pharm 2017; 9:31-36. https://doi.org/10.22159/ijap.2017v9i3.7056

10. Sezer AD, Cevher E, Hatipoglu F, Ogurtan Z, Bas AL, Akbuga J; The use of fucosphere in the treatment of dermal burns in rabbits. Eur J Pharm Biopharm 2008; 69:189 - 198. https://doi.org/10.1016/j.ejpb.2007.09.004

11. Bonacucina G, Martelli S, Palmieri GF, Rheological, mucoadhesive and release properties of carbapol gels in hydrophilic cosolvents; Int J Pharm; 2004; 282:115-130. https://doi.org/10.1016/j.ijpharm.2004.06.012
12. Kumar L, Verma R, Chemical stability studies of bioadhesive topical gel; Int J Pharm Sci; 2011; 3:101-104.

13. Ali J, Khar R, Ahuja A, Kalra R. Buccoadhesive erodible disk for treatment of oro-dental infections: design and characterisation; Int J Pharm; 2002; 238:93-103. https://doi.org/10.1016/S03785173(02)00059-5

14. Thakur R, Aswar Md K, Shams MS, Ali A, Khar RK, Shakeel F; Proniosomal transdermal therapeutic system oflosartan potassium: Development and pharmacokinetic evaluation; J Drug Targeting; 2009; 17:442-449. https://doi.org/10.1080/10611860902963039

15. Acharya A, Kiran Kumar GB, Ahmed MG, Paudel S; A novel approach to increase the bioavailability of candesartan cilexetil by proniosomal gel formulation: in vitro and in vivo evaluation; Int J Pharm Sci; 2016; 8:241-24. 